\title{
Altered Lipid Metabolism during Enteral or Parenteral Nutrition in Rats: Comparison with Oral Feeding
}

\author{
Hirotaka Yamashita, ${ }^{1,2}$ Masaru Iwai, ${ }^{1}$ Koji Nishimura, ${ }^{2}$ \\ Nobuaki KobAYASHI, ${ }^{2}$ and Takashi SHimazU ${ }^{1}$ \\ Departments of ${ }^{1}$ Medical Biochemistry and ${ }^{2}$ Surgery, \\ Ehime University School of Medicine, Shigenobu, Ehime 791-02, Japan
}

(Received September 10, 1992)

\begin{abstract}
Summary To investigate the effects of different routes of alimentation on lipid metabolism, lipid-free nutrients with the same amount of energy and composition were continuously administered via the oral cavity (oral group), directly to the stomach (enteral group), or into the superior caval vein (parenteral group) of unrestrained rats. The body weight gain 1 week after continuous nutrition was greater in enteral and parenteral groups than in the orally-fed group. In comparison with the orally-fed group, the enterally-fed group had significantly greater liver and retroperitoneal adipose tissue weights and hepatic lipid content, whereas the parenterally-fed group produced similar changes to those in the enteral group without significant accumulation of hepatic lipid. The rate of fatty acid synthesis after 1 week of alimentation was 3 -fold higher in the liver in enterally-fed group, and approximately 10-fold higher in white adipose tissue in both enterally- and parenterally-fed groups than in orally-fed group. Plasma concentrations of catecholamines after $6 \mathrm{~h}$ were significantly higher in the orally-fed group than in either the enteral or parenteral group. However, plasma insulin concentrations were not significantly different among the three groups. The results indicate that lipid synthesis and its deposition in the liver and adipose tissue are greatly influenced by the route of alimentation, possibly owing to difference in the early neuro-hormonal responses to different routes of alimentation.

Key Words route of alimentation, oral nutrition, enteral nutrition, parenteral nutrition, lipid metabolism, fatty acid synthesis, retroperitoneal adipose tissue, liver, catecholamines
\end{abstract}

Administration of artificial liquid diet directly into the gastric or intestinal cavity, or into the venous blood is well devised and widely used for clinical purposes. It is especially advantageous for patients who are unable to tolerate oral feeding. Such an alimentation via the parenteral route, however, appeared to cause clinical problems like steatosis or cholestasis $(1-4)$. These observations suggest that 
parenteral nutrition affects lipid metabolism in the body and causes lipid accumulation in liver. In fact, previous studies with animals revealed that total parenteral nutrition caused fat infiltration in the liver $(5,6)$. However, it is not yet clear whether such metabolic alterations after total parenteral nutrition are really due to differences in the nutritional route, since previous studies have not employed the same diet in controls as in parenterally-fed group.

Accordingly, in this study we examined the effects of three different routes of administering the same liquid diet on lipid metabolism in liver and adipose tissues, and analyzed possible contributory factors to an altered lipid metabolism. The results showed that enteral and parenteral nutrition, when compared with oral feeding, caused lipid accumulation in the body partly because of the lack of postprandial responses of the sympatho-adrenal activity.

\section{METHODS}

Animals. Male Sprague-Dawley rats (Clea Japan Inc., Osaka), weighing 220-265 g, were maintained at $25 \pm 1^{\circ} \mathrm{C}$ with a $12 \mathrm{~h}$ light-dark cycle (lights on between 0600-1800) and given free access to laboratory chow (MF, Oriental Yeast Co., Tokyo) and water before experiments.

Surgical procedure. Animals were assigned to three groups and were implanted with tubings under sodium pentobarbital $(50 \mathrm{mg} / \mathrm{kg}$, intraperitoneally) anesthesia as follows. 1) Oral nutrition group: silicon tubing $(0.5 \mathrm{~mm}$ i.d., $1.0 \mathrm{~mm}$ o.d.; $4 \mathrm{~cm}$ length) was implanted into the oral cavity through an incision at the right buccal region (7). 2) Enteral nutrition group: silicon tubing was inserted into the stomach through the cervical portion of esophagus. 3) Parenteral nutrition group: silicon tubing was inserted into the superior caval vein through the right extenal jugular vein. In all groups, distal end of the tubing was pulled under the skin to dorsal portion of the neck and connected to an infusion syringe via the apparatus devised for continuous infusion in unrestrained small animals (Bio-Research Center Inc., Nagoya). In a preliminary experiment using dye, it was confirmed that the orally-fed group consumed all the liquid diet infused.

Experimental schedule. After a 2- to 3-day recovery period with free oral access to laboratory chow and water, continuous administration of the liquid diet was started. Liquid diet composed as listed in Table 1 was infused continuously via three different routes using an infusion pump (SP-50, Nipro Medical Instrument Co., Osaka) at the rate of $72 \mathrm{ml}$ per day, i.e., $82 \mathrm{kcal} /$ day for each rat. During infusion of the diet, the rats were housed individually in special plastic cages to ensure free movement and were given free access to water. After 1 week of alimentation, under anesthesia with sodium pentobarbital (usually at 0900-1100), blood samples were obtained from the inferior caval vein with heparinized syringe. The liver, retroperitoneal white adipose tissue and gastrocnemius muscle were then removed quantitatively, and the serum and tissues were stored at $-20^{\circ} \mathrm{C}$ until assays for metabolites and chemical composition. In some experiments, blood 
Table 1. Composition of liquid diet.

\begin{tabular}{|c|c|}
\hline Ingredient & Amount \\
\hline D-Glucose & $250 \quad(\mathrm{~g} /$ liter $)$ \\
\hline Amino acids ${ }^{1}$ & 31.9 (g/liter) \\
\hline Salt $\operatorname{mix}^{2}$ & $12.4(\mathrm{~g} /$ liter $)$ \\
\hline Vitamin mix & $200 \quad$ (mg/liter) \\
\hline \multicolumn{2}{|l|}{ Metabolizable energy } \\
\hline Total energy $^{3}$ & $1,128 \quad(\mathrm{kcal} /$ liter $)$ \\
\hline Non-protein energy/nitrogen & 204 \\
\hline
\end{tabular}

This solution was continuously infused at the rate of $72 \mathrm{ml} /$ day, i.e., $82 \mathrm{kcal} /$ day to each rat. ${ }^{1}$ Composition of amino acid (g/liter): L-isoleucine, 1.68; L-leucine, 3.75; L-lysine, 3.30; L-methionine, 1.05; L-phenylalanine, 2.81; L-threonine, 1.95; L-tryptophan, 0.39 ; L-valine, 1.35; L-alanine, 1.86; L-arginine, 2.87; L-aspartate, 1.14; L-cysteine, 0.44; L-glutamate, 1.95; L-histidine, 2.43; L-proline, 0.99; L-serine, 0.66; L-tyrosine, 0.11; glycine, $3.21 .{ }^{2}$ Content of salt mix (g/liter): potassium acetate, 2.15; calcium gluconate, 1.91; magnesium sulfate, 1.24; zinc sulfate, 6.0; potassium phosphate monobasic, 1.10. ${ }^{3}$ Total energy was calculated by the sum of D-glucose and amino acids, both energy density being $4 \mathrm{kcal} / \mathrm{g}$.

samples were also taken for catecholamine assay $0,6,24 \mathrm{~h}$ and 7 days after start of alimentation.

Chemical analysis. Triglyceride content of the tissues was determined by the method of Soloni (8) after homogenization with isopropanol. Protein was measured by the method of Lowry et al. (9). Liver glycogen was determined according to a conventional procedure with alkaline extraction, followed by ethanol precipitation, acid hydrolysis, and enzymic glucose assay (10). Plasma glucose was measured by a specific glucose oxidase method (Boehringer-Mannheim, Mannheim, Germany) and plasma concentration of insulin was determined by radioimmunoassay kit (Midori-Juji, Tokyo).

Determination of fatty acid synthesis. The rate of fatty acid synthesis was determined in vivo by measuring the incorporation of ${ }^{3} \mathrm{H}$ from ${ }^{3} \mathrm{H}_{2} \mathrm{O}$ into fatty acids in tissues by the following procedure. Animals were nourished for $24 \mathrm{~h}$ or 7 days under the conditions described above. At the end of alimentation, the animals were injected intraperitoneally with $3 \mathrm{mCi}$ of ${ }^{3} \mathrm{H}_{2} \mathrm{O}$ (ICN Radiochemicals, Irvine, CA). One hour later, they were anesthetized with sodium pentobarbital and blood samples were obtained by cardiac puncture. The liver and retroperitoneal adipose tissue were removed quickly and weighed. Lipids were extracted by homogenizing the tissues with chloroform-methanol $(2: 1, \mathrm{v} / \mathrm{v})$. For isolation of radioactive fatty acids, the lipid extract was washed 3 times by the procedure of Folch et al. (11), saponified with ethanolic $\mathrm{KOH}$ at $80^{\circ} \mathrm{C}$ for $2 \mathrm{~h}$, acidified with sulfuric acid, and then extracted with petroleum ether as described previously (12). The ${ }^{3} \mathrm{H}$-radioactivities of the final extract and body water (sera) were measured in a liquid scintillant (2,5-diphenyloxazole $0.58 \%$ and $2,2^{\prime}-p$-phenylene-bis(5-phenyl oxazole) 
$0.02 \%$ in xylene) using Tri-Carb scintillation counter (Hewlett-Packard, model 300C, Packard Instrument Co., Downers Grove, IL) with automatic correction for quenching. The rate of fatty acid synthesis was calculated as $\mu \mathrm{mol}$ of fatty acid synthesized per hour as $\left(\mathrm{dpm}{ }^{3} \mathrm{H}\right.$ in fatty acids)/(dpm ${ }^{3} \mathrm{H}$ in $\mu$ g-atom hydrogen in body water) divided by $13.3(13,14)$.

Assay of epinephrine and norepinephrine. Plasma concentrations of epinephrine and norepinephrine were determined at $0 \mathrm{~h}, 6 \mathrm{~h}, 24 \mathrm{~h}$, and 7 days after initiation of alimentation, by modification of the HPLC method of Refshauge et al. (15). At the end of each period of administration, rats were anesthetized with sodium pentobarbital and blood samples were obtained from the inferior caval vein. Two milliliter aliquot of the plasma was mixed with $1.5 \mathrm{ml}$ of $0.2 \mathrm{~N}$ perchloric acid containing $1 \%$ sodium bisulfite and $1 \mathrm{~mm}$ EDTA. The mixture was then centrifuged at $5,000 \times g$ for $10 \mathrm{~min}$, and aliquots of the resulting supernatant were treated with alumina at $\mathrm{pH}$ 8.5. After washing alumina with water, catecholamines were eluted with $0.2 \mathrm{~N}$ acetic acid and assayed using an HPLC system for catecholamine analysis (Tosoh Co., Tokyo).

Statistical analysis. Results are expressed as the $\mathbf{M} \pm$ SEM. The data of fatty acid synthesis rate and plasma catecholamine concentration were analyzed by two-way analysis of variance (ANOVA) and other data were analyzed by one-way analysis of variance followed by the Newman-Keuls' test for multiple comparisons (16). The data of plasma catecholamine concentration were log transformed before ANOVA. Statistical significance was selected at a level of $p<0.05$.

\section{RESULTS}

First, to examine whether the implantation of silicon tubing for alimentation itself has an influence on growth and tissue weights, three groups of operated rats (weighing 240-278 g, 5 for each group) were housed in the same plastic cages as in the experimental schedule and given orally free access to laboratory chow and water for 1 week, instead of being given the liquid diet. The implantation of silicon tubing did not disturb oral feeding. The mean increments of body weight were $50 \pm 3,43 \pm 6$, and $46 \pm 5 \mathrm{~g}$ for the oral, enteral, and parenteral implantation, respectively. There were no significant differences in body weight gain and in weights of the retroperitoneal white adipose tissue, gastrocnemius muscle, and liver among these three groups.

Changes in body weight and tissue weight after infusion of liquid diet

Continuous infusion of the same amount of liquid diet as in Table 1 for 1 week increased the body weight in all three experimental groups (Table 2). The body weight gain in both enterally- and parenterally-fed groups was significantly greater than that in the orally-fed group.

One week after continuous infusion of the liquid diet, tissue weight was also measured (Table 2). There was no significant difference in the weight of gastroc- 
Table 2. Body weight gain and organ weights after 7 days of alimentation by three different routes.

\begin{tabular}{lccc}
\hline & $\begin{array}{c}\text { Oral } \\
(\mathrm{g})\end{array}$ & $\begin{array}{c}\text { Enteral } \\
(\mathrm{g})\end{array}$ & $\begin{array}{c}\text { Parenteral } \\
(\mathrm{g})\end{array}$ \\
\hline Initial body wt. & $232 \pm 4$ & $236 \pm 5$ & $237 \pm 7$ \\
Change of body wt. & $16 \pm 1$ & $37 \pm 2^{*}$ & $39 \pm 2^{*}$ \\
Gastrocnemius muscle & $2.9 \pm 0.2$ & $3.2 \pm 0.1$ & $3.1 \pm 0.2$ \\
Retroperitoneal white adipose tissue & $1.2 \pm 0.1$ & $2.2 \pm 0.2^{*}$ & $2.6 \pm 0.2^{*}$ \\
Liver & $10.4 \pm 0.1$ & $12.0 \pm 0.3^{*}$ & $11.3 \pm 0.3^{*}$ \\
\hline
\end{tabular}

Values are $\mathbf{M} \pm \mathrm{SEM}$ of 10 rats. Rats were infused with liquid diet shown in Table 1, by three different routes continuously for 7 days. * Significantly different from orallyfed group $(p<0.05)$, as determined by Newman-Keuls' multiple range test.

Table 3. Changes in chemical composition of liver after 7 days of alimentation by three different routes.

\begin{tabular}{lccc}
\hline & $\begin{array}{c}\text { Oral } \\
(\mathrm{mg} / \mathrm{g} \text { wet tissue })\end{array}$ & $\begin{array}{c}\text { Enteral } \\
(\mathrm{mg} / \mathrm{g} \text { wet tissue })\end{array}$ & $\begin{array}{c}\text { Parenteral } \\
(\mathrm{mg} / \mathrm{g} \text { wet tissue })\end{array}$ \\
\hline Glycogen & $45.1 \pm 4.4$ & $45.9 \pm 3.7$ & $46.1 \pm 4.0$ \\
Protein & $174 \pm 5$ & $171 \pm 4$ & $174 \pm 5$ \\
Triglyceride & $11.5 \pm 1.9$ & $48.3 \pm 5.7^{*}$ & $14.5 \pm 1.6$ \\
\hline
\end{tabular}

Values are $\mathbf{M} \pm$ SEM of 10 rats, same as in Table 2. Rats were administered liquid diet by three different routes continuously for 7 days. ${ }^{*}$ Significantly different from orally-fed group $(p<0.05)$, as determined by Newman-Keuls' multiple range test.

nemius muscle among the three experimental groups. In contrast, the retroperitoneal white adipose tissue was greater, possibly reflecting more accumulation of triglycerides, in the enteral and parenteral groups than in the orally-fed group. Liver weight was also heavier in either the enterally- or parenterally-fed group than in the orally-fed group.

\section{Chemical composition of liver}

The contents of protein, glycogen, and triglycerides in the liver after 1 week of alimentation are shown in Table 3. The hepatic contents of protein and glycogen did not change significantly in all three experimental groups; however, hepatic content of triglycerides increased remarkably in the enterally-fed group, accumulating 4 times as much lipids as in the orally-fed group. A slight increase in hepatic triglycerides in the parenterally-fed group was not statistically significant.

Plasma concentrations of glucose, triglycerides, free fatty acids, and insulin

Plasma concentrations of glucose, triglycerides, free fatty acids, and insulin were measured at the end of 1 week alimentation (Table 4). Plasma glucose concentration tended to be higher in the orally-fed group and was lower in the 
Table 4. Plasma concentrations of glucose, triglyceride, FFA, and insulin after 7 days of alimentation by three different routes.

\begin{tabular}{lrrr}
\hline & Oral & Enteral & Parenteral \\
\hline Glucose $(\mathrm{mg} / \mathrm{dl})$ & $143.8 \pm 4.5$ & $133.9 \pm 4.9$ & $118.1 \pm 5.7^{*}$ \\
Triglyceride $(\mathrm{mg} / \mathrm{dl})$ & $61.5 \pm 6.8$ & $71.8 \pm 9.1$ & $50.7 \pm 6.9$ \\
Free fatty acid $(\mu \mathrm{Eq} /$ liter $)$ & $63.7 \pm 5.7$ & $67.1 \pm 5.2$ & $63.1 \pm 4.6$ \\
Insulin $(\mu \mathrm{U} / \mathrm{ml})$ & $30.9 \pm 3.8$ & $37.2 \pm 4.7$ & $42.9 \pm 7.0$
\end{tabular}

Values are $\mathrm{M} \pm \mathrm{SEM}$ of 10 rats, same as in Table 2. Rats were administered liquid diet by three different routes continuously for 7 days. Blood samples were obtained 20 min after the end of alimentation. * Significantly different from orally-fed group $(p<0.05)$, as determined by Newman-Keuls' multiple range test.

parenterally-fed group. Plasma insulin concentration had tendency opposite to the glucose concentration, but the differences were not statistically significant. No significant differences of the triglycerides and free fatty acid concentrations were observed among the three groups.

\section{Rate of fatty acid synthesis in liver and adipose tissue}

The increases in tissue weight and triglyceride content in the liver and adipose tissue after enteral or parenteral nutrition suggest that some alterations of lipid metabolism have been produced in these tissues by the different routes of alimentation. The rate of fatty acid synthesis was then determined by measuring the incorporation of ${ }^{3} \mathrm{H}$ from ${ }^{3} \mathrm{H}_{2} \mathrm{O}$ into fatty acids after $24 \mathrm{~h}$ and 7 days of alimentation (Fig. 1). At the beginning (after $24 \mathrm{~h}$ ) of administration of the liquid diet, the rates of fatty acid synthesis in the liver and retroperitoneal adipose tissue were extremely high regardless of the route of alimentation, as compared with normal values obtained from fed rats (approximately 2.5 and $0.8 \mu \mathrm{mol}$ fatty acid synthesized per $\mathrm{g}$ tissue per hour for the liver and retroperitoneal adipose tissue, respectively (12)). This high rate of fatty acid synthesis may come from the composition of liquid diet devoid of fat. It has been known that fat-free diet increases the activities of acetyl-CoA carboxylase and fatty acid synthetase (17). After 7 days of alimentation, however, the synthetic rate approached normal values both in the liver and white adipose tissue under oral nutrition, whereas it decreased significantly only in the liver under parenteral nutrition (Fig. 1). The high rates of fatty acid synthesis in both tissues were maintained under enteral nutrition. These results indicated that the continued high rate of fatty acid synthesis was necessary for accumulation of triglycerides in liver and white adipose tissue.

\section{Plasma concentrations of norepinephrine and epinephrine}

Catecholamines have been reported to affect lipogenic activity in adipocytes $(18,19)$ and hepatocytes $(20,21)$. To investigate if activity of the sympathoadrenal system might be altered by different routes of alimentation, plasma concen- 
Liver
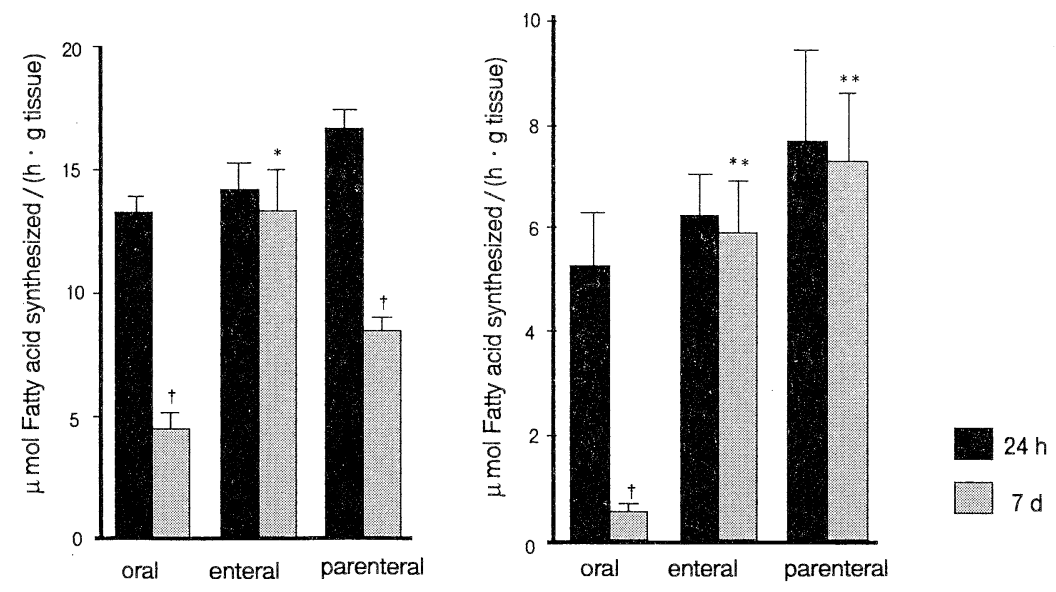

Fig. 1. Rate of fatty acid synthesis in the liver and retroperitoneal adipose tissue 24 $\mathrm{h}$ and 7 days after start of alimentation. The synthetic rate was measured by the incorporation of ${ }^{3} \mathrm{H}_{2} \mathrm{O}$ into fatty acids as described under Methods. Each column represents the $\mathrm{M} \pm \mathrm{SEM}$ of 6 rats. ${ }^{*}$ Significantly different $(p<0.05)$ from orally and parenterally-fed groups, ${ }^{* *}$ significantly different $(p<0.05)$ from the oral group, and ${ }^{\dagger}$ significantly different $(p<0.05)$ from 24 -h values, as determined by Newman-Keuls' multiple range test.
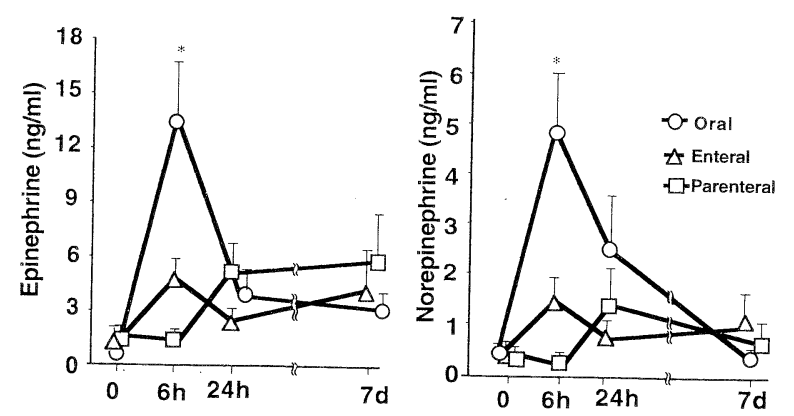

Fig. 2. Plasma concentrations of epinephrine and norepinephrine during administration of the liquid diet. Each point is the $\mathrm{M} \pm \mathrm{SEM}$ of 5 rats. Rats were administered liquid diet via three different routes continuously for 7 days. ${ }^{*}$ Significantly different $(p<0.05)$ from initial value as determined by Newman-Keuls' multiple range test. 
trations of epinephrine and norepinephrine were measured during administration of the liquid diet. Figure 2 shows that the plasma concentrations of epinephrine and norepinephrine were both elevated in orally-fed group $6 \mathrm{~h}$ after start of alimentation, and returned to the normal levels by day 7 . Such a transient increase in catecholamine concentrations in the early phase of alimentation was not observed in enterally-fed and parenterally-fed groups.

\section{DISCUSSION}

The results of the present study demonstrate that enteral and parenteral nutrition in rats causes greater gain of body and adipose tissue weights and an accumulation of triglycerides in liver as compared with oral feeding with the same liquid diet (Table 2 and 3). Such increases in the triglyceride content and adipose tissue weight appear to be due mainly to changes in the rate of fatty acid synthesis (Fig. 1). Since all experimental groups were administered the same liquid diet, the alterations in lipid metabolism could be attributed to the differences in the routes of alimentation.

The greater gain of body weight and greater fattening in the enterally- and parenterally-fed groups may reflect a reduced energy expenditure, presumably owing to a lack of oropharyngeal sensory stimuli responsible for a diet-induced thermogenesis in brown adipose tissue. It has already been reported that tubefeeding by intragastric tube causes increases in body weight gain $(22,23)$, body fat, and liver and white adipose tissue weights compared with oral feeding (24), but decreases functional activities of the interscapular brown adipose tissue (24). Although metabolic changes in brown adipose tissue were not analyzed in the present study, we confirmed that the increase in liver and white adipose tissue weights in the enterally-fed group was probably due to the accumulation of triglycerides (Table 3). The rate of fatty acid synthesis increased in both tissues in this group and was maintained at a high level during 7 days of the nutritional schedule (Fig. 1).

Parenteral nutrition has been reported to cause fatty infiltration in rat liver $(5$, 6). The parenterally-fed group in our study produced an increase in white adipose tissue weight and insignificant increase in triglyceride content in the liver (Tables 2 and 3). The rate of fatty acid synthesis in liver of this group was still higher than that in orally-fed group at the end of alimentation for 7 days (Fig. 1). It is not known why hepatic content of triglycerides was not increased significantly in the parenterally-fed groups as in previous studies. However, it may be related to the differences in experimental conditions. In the previous studies, the orally-fed group (control group) was given solid diet with different composition than the liquid diet that was given to the parenteral group $(5,6)$. Although the parenterally-fed group in our present study did not produce significant accumulation of liver triglycerides, the energy content of the liquid diet appeared to be sufficient for growth, judging from the significant increase in body weight gain (Table 2). Knowing that the liver 
triglyceride content in the parenterally-fed group was not significantly increased despite the elevated rate of fatty acid synthesis relative to the orally-fed group at the end of alimentation (Fig. 1), it is likely that the release of triglycerides from liver as lipoprotein could be enhanced after parenteral nutrition. Another possibility is that the lower fat content of liver without significant increase in the plasma triglyceride concentration in parenterally-fed rats may be due, in part, to an enhanced peripheral tissue uptake of plasma triglycerides.

The rate of hepatic fatty acid synthesis in the parenterally-fed group was about two-third of that in the enterally-fed group (Fig. 1). This result contrasts with those of Lanza-Jacoby (6), who observed no significant difference in hepatic lipogenesis between the enterally- and parenterally-fed groups. The reason for these different observations is poorly understood at present. However, different composition of the liquid diet (the lower energy-nitrogen ratio in ours) and the different time of measurement of lipogenesis may account for the discrepancy between the previous and present studies. It is also possible that the different effects of enteral and parenteral nutrition on hepatic lipogenesis may result from different responses of certain hormonal factors, particularly of gastrointestinal hormones, even though we could not detect significant changes in the plasma insulin concentrations. Since there was no significant difference in lipogenic activity in white adipose tissue between the enterally- and parenterally-fed groups, it seems likely that the lipogenic response of liver is more sensitive than that of adipose tissue to the possible changes in gastrointestinal humoral factors.

The mechanism by which alterations of lipid metabolism are produced after enteral and parenteral nutrition but not after oral feeding is not yet totally clear. However, it is relevant to note that the plasma concentrations of several metabolic substrates and hormones change in the early stage of oral feeding, such as the rapid and transient elevations of the plasma glucose, free fatty acids, insulin, and catecholamines (25-29). These metabolic changes in response to oral feeding disappeared when nutrient was administered directly into the gastrointestinal tract to escape the "cephalic phase" of feeding (26). In the present study we also observed the elevation of plasma catecholamine concentration $6 \mathrm{~h}$ after oral feeding, indicating activation of the sympathetic nervous system in the early period of oral feeding but not with other routes of alimentation (Fig. 2). Although this increased level of plasma catecholamines in the orally-fed group was not sustained during the whole nutritional schedule, the lack of this response to nutrient intake in the enterally- and parenterally-fed groups may contribute, at least in part, to the altered lipid metabolism and resultant fat accumulation in specific organs in these groups.

The experiment protocol was approved by the Animal Studies Committee of Ehime University. This study was supported in part by a Grant-in-Aid for Scientific Research from the Ministry of Education, Science and Culture, Japan. 


\section{REFERENCES}

1) Sheldon, G. F., Petersen, S. R., and Sanders, R. (1978): Hepatic dysfunction during hyperalimentation. Arch. Surg., 113, 504-508.

2) Lindor, K. D., Fleming, C. R., Abrams, A., and Hirschkorn, M. A. (1979): Liver function values in adults receiving total parenteral nutrition. J. Am. Med. Assoc., 241, 2398-2400.

3) Kaminski, D. L., Adams, A., and Jellinek, M. (1980): The effect of hyperalimentation on hepatic lipid content and lipogenic enzyme activity in rats and man. Surgery, 88, 93-100.

4) Stein, T. P., Buzby, G. P., Gertner, M. H., Hargrove, W. C., Leskiw, M. J., and Mullen, J. L. (1980): Effect of parenteral nutrition on protein synthesis and liver fat metabolism in man. Am. J. Physiol., 239, G280-G287.

5) Hall, R. I., Grant, J. P., Ross, L. H., Coleman, R. A., Bazovic, M. G., and Quarfordt, S. H. (1984): Pathogenesis of hepatic steatosis in the parenterally fed rat. J. Clin. Invest., 74, 1658-1668.

6) Lanza-Jacoby, S. (1986): Effect of continuous and discontinuous intravenous or intragastric total parenteral nutrition in rats on serum lipids, liver lipids and liver lipogenic rates. J. Nutr., 116, 733-741.

7) Hara, E., and Saito, M. (1980): Diurnal changes in plasma glucose and insulin responses to oral glucose load in rats. Am. J. Physiol., 238, E463-E466.

8) Soloni, F. G. (1971): Simplified manual micromethod for determination of serum triglycerides. Clin. Chem., 17, 529-534.

9) Lowry, O. H., Rosebrough, N. J., Farr, A. L., and Randall, R. J. (1951): Protein measurement with the Folin phenol reagent. J. Biol. Chem., 193, 265-275.

10) Geary, N., Langhans, W., and Scharrer, E. (1981): Metabolic concomitants of glucagon-induced suppression of feeding in the rat. Am. J. Physiol., 241, R330-R335.

11) Folch, J., Lees, M., and Sloane-Stanley, G. H. (1957): A simple method for the isolation and purification of total lipids from animal tissues. J. Biol. Chem., 226, 497509.

12) Shimazu, T., and Takahashi, A. (1980): Stimulation of hypothalamic nuclei has differential effects on lipid synthesis in brown and white adipose tissue. Nature (Lond.), 284, 62-63.

13) Windmueller, H. G., and Spaeth, A. E. (1966): Perfusion in situ with tritium oxide to measure hepatic lipogenesis and lipid secretion. J. Biol. Chem., 241, 2891-2899.

14) Jungas, R. L. (1968): Fatty acid synthesis in adipose tissue incubated in tritiated water. Biochemistry, 7, 3708-3717.

15) Refshauge, C., Kissinger, P. T., Dreiling, R., Blank, L., Freeman, R., and Adams, R. N. (1974): New high performance liquid chromatographic analysis of brain catecholamines. Life Sci., 14, 311-322.

16) Bruning, J. L., and Kintz, B. L. (1987): The Newman-Keuls' multiple-range test, in Computational Handbook of Statistics, Vol. 3, ed. by Bruning, J. L., and Kintz, B. L., Scott, Foresman and Company, London, pp. 122-124.

17) Craig, M. C., Dugan, R. E., Muesing, R. A., Slakey, L. L., and Porter, J. W. (1972): Comparative effects of dietary regimens on the levels of enzymes regulating the 
synthesis of fatty acids and cholesterol in rat liver. Arch. Biochem. Biophys., 151, 128136.

18) $\mathrm{Ng}$, T. B. (1990): Studies on hormonal regulation of lipolysis and lipogenesis in fat cells of various mammalian species. Comp. Biochem. Physiol., 97B, 441-446.

19) Casanova,L., Alonso, G., and Moreno, F. J. (1990): Some aspects of metabolic adaptations in lipid metabolism during starvation are mimicked by epinephrine in rat adipocytes. Int. J. Biochem., 22, 19-23.

20) Roncero, C., Lorenzo, M., Fabregat, I., and Benito, M. (1989): Rates of lipogenesis in fetal hepatocytes in suspension and in primary culture: Hormonal effects. Biochim. Biophys. Acta, 1012, 320-324.

21) Stark, B., and Keller, U. (1987): $\alpha_{1}$-Adrenergic stimulation of ketogenesis and fatty acid oxidation is associated with inhibition of lipogenesis in rat hepatocytes. Experientia, 43, 1104-1106.

22) Rothwell, N. J., and Stock, M. J. (1978): A paradox in the control of energy intake in the rat. Nature (Lond.), 273, 146-147.

23) Rothwell, N. J., and Stock, M. J. (1979): Regulation of energy balance in two models of reversible obesity in the rat. J. Comp. Physiol. Psychol., 93, 1024-1034.

24) Saito, M., Minokoshi, Y., and Shimazu, T. (1989): Metabolic and sympathetic nerve activities of brown adipose tissue in tube-fed rats. Am. J. Physiol., 257, E374-E378.

25) LeBlanc, J., Cabanac, M., and Samson, P. (1984): Reduced postprandial heat production with gavage as compared with meal feeding in human subjects. Am. J. Physiol., 246, E95-E101.

26) Diamond, P., and LeBlanc, J. (1987): Hormonal control of postprandial thermogenesis in dogs. Am. J. Physiol., 253, E521-E529.

27) Hell, N. S., Iwai, M., and Shimazu, T. (1988): Liver phosphorylase activation during early phase of feeding behavior: A neurohumoral regulation. Physiol. Behav., 43, 383387.

28) Steffens, A. B. (1986): Influence of the hypothalamus on glucose and free fatty acid release during physical and emotional stimulation of the rat, in Emotions: Neuronal and Chemical Control, ed. by Oomura, Y., Japan Scientific Societies Press, Tokyo, pp. 355-367.

29) Strubbe, J. H., and Steffens, A. B. (1975): Rapid insulin release after ingestion of a meal in the unanesthetized rat. Am. J. Physiol., 229, 1019-1022. 